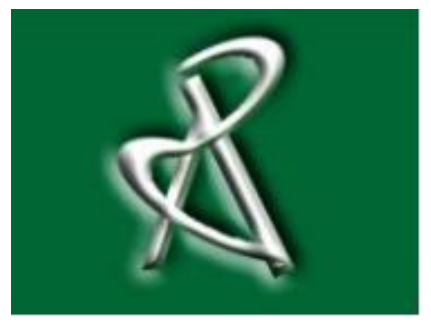

Available online at www.academicpaper.org

\section{Academic @ Paper}

ISSN 2146-9067

International Journal of Automotive Engineering and Technologies

Vol. 4, Issue 3, pp. 130-138, 2015
International Journal of Automotive

Engineering and Technologies

http://www.academicpaper.org index.php/IJAET

Original Research Article

\title{
TIG Melted Surface Modified Titanium Alloy for Cylinder Liner Application
}

S.A. Adeleke ${ }^{1}$, and M.A. Maleque ${ }^{1 *}$

${ }^{1}$ Department of Manufacturing and Materials Engineering International Islamic University Malaysia, P.O. Box 10, 50728, Kuala Lumpur, Malaysia

Received 11 January 2015 Accepted 26 August 2015

\begin{abstract}
Tungsten inert gas (TIG) surface modification with Fe-based alloy can give protection against wear and corrosion of metallic component material. In this study, an attempt has been made to explore deposition of Fe-based alloy on commercial purity titanium (CP-Ti) by TIG torch melting process to improve resistance of substrate to wear. Three different powder blends with nominal composition of $97 \mathrm{Fe} 2 \mathrm{C} 1 \mathrm{Si}$, 94Fe 4C2Si and 91Fe6C3Si were separately melted on CP-Ti using a conventional TIG welding torch produced at $100 \mathrm{~A}$ and energy input $1350 \mathrm{~J} / \mathrm{mm}$. Analysis of the results showed that TIG torch produced melt pools geometry with good metallurgical bonding with the substrate. The melt microstructures consisted of variety of different TiC precipitates. Pores were conspicuously seen on the melt microstructure modified with highest carbon content. Both micro hardness and wear resistance showed a significant improvement particularly after TIG coating with 94Fe4C2Si. Thus, it appears that an optimized composition of TIG coated with $94 \mathrm{Fe} 4 \mathrm{C} 2 \mathrm{Si}$ was best to control abrasive resistance and for the application of cylindrical liner.
\end{abstract}

Key Words: Surface modification, TIG, Cylinder liner, Fe-based alloy and Commercial purity titanium (CP-Ti)

*Corresponding Author:

E-mail: maleque@iium.edu.my 


\section{Introduction}

There has been an increasing interest in light weight structural automotive material to achieve a reduction in average fuel consumption over the last ten decades. Titanium with its good strength to weight ratio and low density is a potential candidate material to realize this, but its surface properties need to be tailored in order to meet specific challenges in an engine block such as abrasive wear, corrosion resistance and the emission caused by lubricating oil [1]. Owing to this, several surface technologies have been suggested by engine manufacturers. Among these technologies, TIG modification is a promising cost effective technique that is capable of solving problems such as wear, corrosion and thermal stability which could restrict titanium material for cylinder liner application [2-4]. To ensure good thermal conductivity and to keep the temperature of the inner surface of the liner sufficiently low, a good metallurgical bonding between the liner and the engine block is one of the most critical factors [5]. Advances in surface modification of industrial part with TIG have shown a huge success in this aspect [6]. A coated surface obtained by TIG technique has the potential to produce a dense coating with good metallurgical bonding to the base material. Tungsten inert gas by means of surface modification is a process by which an alloy powder of desirable composition is homogeneously deposited onto the surface of soft materials (usually titanium or low alloy steel) by melting with a view to increasing hardness and wear resistance without significant loss in the bulk material properties.

The reduction of friction losses in automotive engines offers big potential when looking for possibilities to cut down fuel consumption. Iron based alloy provides itself a good tribological coating material. In recent years, many investigations have been carried out on iron based alloy as coating material to improve the hardness and wear resistance of industrial part [7-9]. The important features of Fe-based alloy are its good wear resistance, high hardness and good wettability. The two alloying elements such as carbon and silicon are responsible for carbide formations with improve wear resistance. In the $\mathrm{Fe}-\mathrm{Cr}-\mathrm{C}-\mathrm{Si}$ coating improved on CP-Ti with TIG method depending on processing conditions, it was found that the as deposited coatings contained higher volume fractions of carbides which gave rise to increase in micro hardness and wear resistance [4]. Wang et al. [10] investigated the wear properties of in situ TiC/ FeCrBSi composite coating using TIG process on AISI 1045. They reported that $\mathrm{TiC}$ reinforced composite coatings gave better hardness and wear resistance. Sabet et al. [8] investigated the microstructure and wear resistance of $\mathrm{Fe}-\mathrm{Cr}-\mathrm{C}$ on AISI 1010 mild steel using TIG melting process. The result showed a significant improvement in both hardness and wear resistance.

In this study, an attempt is made to explore the preparation of coating on CP-Ti using Fe$\mathrm{C}$-Si ternary mixture preplaced powder on CP-Ti under TIG melting. A detailed investigation concerning the evolution of microstructure, melt geometry and mechanical properties (in terms of micro hardness and wear resistance) were examined.

\section{Materials and Experimental Method}

Commercial purity titanium (CP-Ti) was used as a substrate in the form of $50 \mathrm{~mm} \times 40$ $\mathrm{mm}^{2}$ with a $10 \mathrm{~mm}$ thickness in TIG processing experiments. Before coating, the specimens were ground and cleaned with acetone. Three different elemental mixtures of $\mathrm{Fe}-\mathrm{C}-\mathrm{Si}$ powder blends were used as the coating materials. The compositions of CPTi along with the powders used for surface coating are given in Table 1 . The powder preplaced mixture (PPM) was first made using a pasty mass by mixing with alcohol and then applies to the substrate surface. The powder coated substrate was melted under a constant operating current of $100 \mathrm{~A}$ and energy input $1350 \mathrm{~J} / \mathrm{mm}$ using TIG torch process. Detail information on the processing procedures can be found in the literature [6]. Conventional characterization techniques 
such as scanning electron microscope (SEM), EDX, X-ray diffraction were employed for studying the microstructure and analysis of the modified layer. Microhardness values with $500 \mathrm{gf}$ load were taken across the modified zone. Due to slight variation in the hardness values, three different points for each reading were taken and average value was recorded. The dry sliding wear resistance of the surface modified were determined at room temperature using ball-on-plate wear tester under a constant load $10 \mathrm{~N}$ and varying sliding speeds. The counterpart was alumina steel with a hardness of $1750 \mathrm{~kg} / \mathrm{mm}^{2}$ and a ball diameter of $6 \mathrm{~mm}$. Worn surfaces were analyzed using SEM and wear rate were calculated according to the equation in literature [11].

Table 1. Chemical compositions of CP-Ti and powders preplaced mixtures (PPM) for surface modification (wt.\%)

\begin{tabular}{|l|c|c|c|c|c|c|c|}
\hline Chemical component & $\mathrm{Ti}$ & $\mathrm{Fe}$ & $\mathrm{C}$ & $\mathrm{Si}$ & $\mathrm{H}$ & $\mathrm{O}$ & $\mathrm{N}$ \\
\hline CP-Ti & 99.425 & 0.3 & 0.08 & - & 0.015 & 0.15 & 0.03 \\
\hline 97Fe2C1Si (PPM1) & - & 97 & 2 & 1 & - & - & - \\
\hline 94Fe4C2Si (PPM2) & - & 94 & 4 & 2 & - & - & - \\
\hline 91Fe6C3Si (PPM3) & - & 91 & 6 & 3 & - & - & - \\
\hline
\end{tabular}

\section{Results and Discussion}

\section{A. Melt configuration and microstructures.}

The widths and depths of the PPM tracks processed under different powder compositions are given in Table 2. The depth and the width of the melt zone showed that the geometric configuration of these resolidified melt layers were influenced by the amount of preplaced powder mixtures where the melt width and depth showed a complete variant with different powder compositions at the same energy input $(1350 \mathrm{~J} / \mathrm{mm})$. Comparing the results obtained from PPM2 with that of PPM1 and PPM3, it can be seen that track processed with PPM2 produced a melt depth of $1.52 \mathrm{~mm}$ and a higher thickness of $1.2 \mathrm{~mm}$ than other two PPMs CP-Ti modified surface. The formation of larger melt depth is presumed to be associated with reactive nature of carbon with titanium in the melt matrix. With higher amount of carbide formation, a larger amount of thermal energy released which eventually resulting in larger melt depth under PPM2 in this investigation. In the sample processed with PPM1 under the same energy input, the decreased melt depth observed can be explained in terms of carbon concentration in the melt pool. At lower carbon concentration (PPM1), a smaller amount of carbide is expected to form which ultimately release lesser exothermic energy with shallower melt depth. In PPM3 track, the decreased melt depth observed in comparison with PPM2 and PPM1 is due to reduction of solubility of carbon in Ti melt matrix. At higher amount of silicon in PPM3, the possibility of formation of carbides reduces as silicon reduces the solubility of carbon in Ti melt matrix [12]. As a result, less amount of carbide was formed resulting less amount of thermal energy as compared to that of PPM2 track with higher population of carbides. Hence, shallower melt depth was obtained for PPM3. On the other hand, the melt width size for PPM3 track was about 1.4 times greater than PPM1 track. For different preplaced powder mixtures, the melt size does not increase linearly with the increased in powder compositions. In general, the melt size is controlled by different processing parameters such as operating current, electrode speed and arc length [13], thus, the width size varies with different powder preplacement mixtures.

Fig. 1 shows the melt configuration for the three different PPM tracks at energy input of $1350 \mathrm{~J} / \mathrm{mm}$. The melt cross-sections obtained were found to be hemispherical in shape. The Gaussian energy distribution which is responsible for providing greater heat intensity in the middle of the melt and gradually decreases to both edges leading to the formation of hemispherical shape melt pool. This phenomenon was also explained 
by other researchers using laser and TIG melting processes where the hemispherical melt pool shapes are formed by the Gaussian energy distribution in the coating [13]. The continuous fusion line observed between the coating layer and the substrate (Fig. 1) proved that good metallurgical bonding was incurred in the melt zone due to appropriate mixing and dissolving of PPM (Fe, C and $\mathrm{Si}$ ).

Table 2. Melt depth and width of PPM tracks produced

\begin{tabular}{|c|c|c|c|c|c|c|}
\hline Energy input J/mm & \multicolumn{2}{|c|}{ PPM1 track } & \multicolumn{2}{c|}{ PPM2 track } & \multicolumn{2}{c|}{ PPM3 track } \\
\hline \multirow{2}{*}{1350} & Depth [mm] & Width [mm] & Depth [mm] & Width [mm] & Depth [mm] & Width [mm] \\
\cline { 2 - 7 } & 1.27 & 8.30 & 1.52 & 8.27 & 1.26 & 11.5 \\
\hline
\end{tabular}

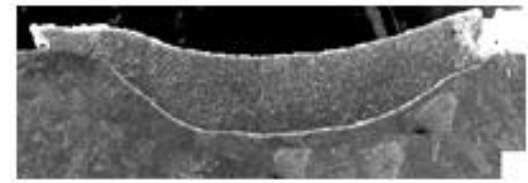

(a)

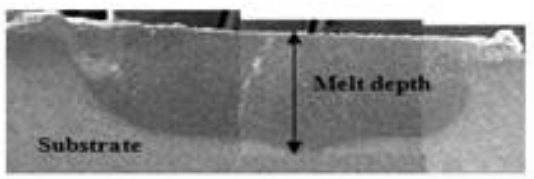

(b)

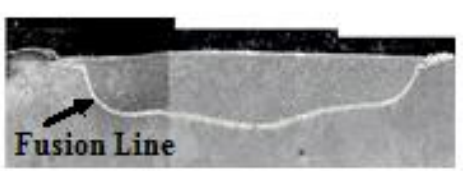

(c)

Figure 1 Melt configurations demonstrating good metallurgical bonding with the CP-Ti substrate at different PPM tracks: (a) PPM1, (b) PPM2 and (c) PPM3.

Melting of commercial purity titanium with preplaced powder mixtures produced dendritic microstructures in the melt pool. Fig. 2 shows the dendrites produced with three different PPM tracks. The vertical section of the track produced with PPM3 showed needle like microstructures which are different from PPM1 and PPM2 tracks whereby puny like and armed typed microstructures were obtained respectively. With PPM3 powder mixture incorporation, the melt pool layer was characterized with pores and voids which were generally absent in PPM1 and PPM2 tracks. The presence of pores on this track suggests that the formation is associated with amount of PPM powder mixtures in the melt. During solidification, the presence of precipitation of carbides which had further increased the viscosity caused sudden freezing of the melt and gas evolution resulting in pore formation.

The melt microstructure of this track consisted of prominent ferrite phase grains. The emergence of this ferrite phase is attributed to reduction of carbon solubility in titanium melt matrix by higher amount of silicon content. With the increased in silicon content in Fe-C ternary alloy system, the graphitization reaction occur with the decreased tendency for metal to form thermodynamically stable microstructure [12]. Silicon also has the effect of raising eutectoid temperature in iron-carbon alloy system and hence with higher amount of silicon content more ferrite structure is formed [15]. At lower powder preplaced mixtures (PPM1), the dendrite size was very small but much larger with (PPM2). The enlarged or extended dendrites in the PPM2 track are thought to be associated with the increased carbon content in PPM. The amount of carbon is believed to have influenced the growth of dendrites and their concentration in the melt. At energy input $1350 \mathrm{~J} / \mathrm{mm}$, the melt is assumed to absorb more PPM resulting greater concentration of carbon in the melt pool forming larger dendrites. The formation of flow loops in the melt cross-section with high concentration of dendrites is due to the Maragoni convectional fluid flow [16]. The preplaced powder mixture flowed along the loop in the melt resulting in high concentration of PPM in the melt. Lowering powder preplaced mixtures (PPM1) in the melt at the same energy input subsequently increased the cooling rate, which is believed to be a factor in producing fewer and smaller dendrites puny particles in the microstructure. Therefore, the feature of the microstructure is suggested to be related to nucleation and growth kinetics of the dendrites which depends on the concentration of PPM in the melt pool and the cooling rate. 


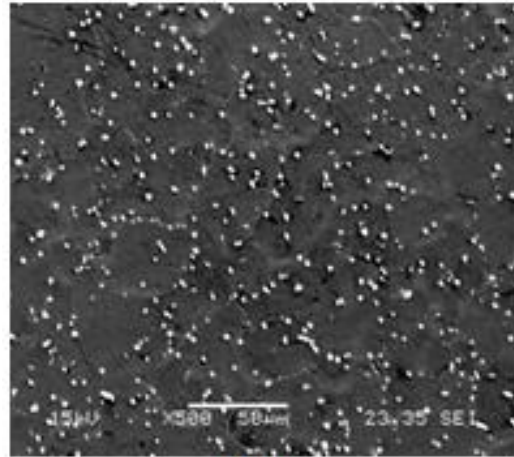

(a)

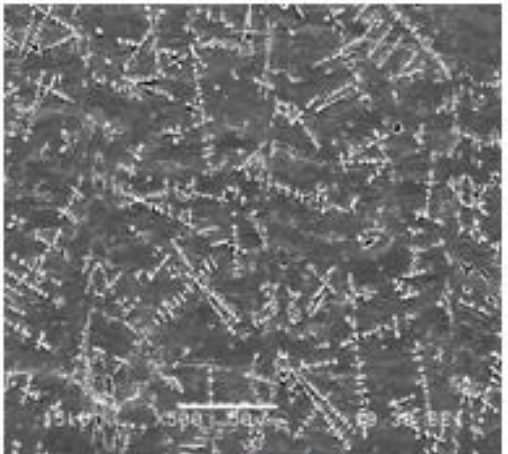

(b)

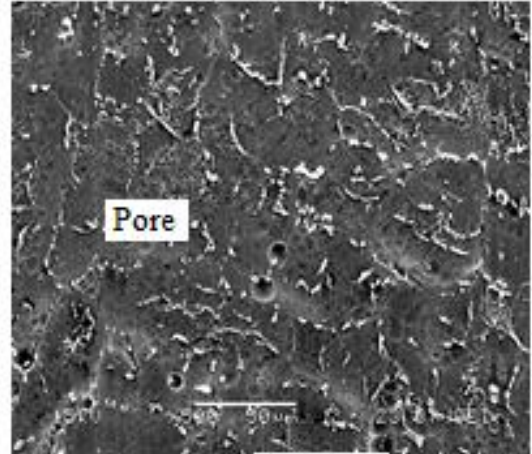

(c)

Figure 2 SEM micrographs showing melt microstructure of the modified CP-Ti at different $\mathrm{PPM}_{\mathrm{s}}$ : (a) PPM1, (b) PPM2 and (c) PPM3

Fig. 3 shows the EDX analyses along with the X-ray diffraction pattern of modified track. Elemental analysis within the dendrite in PPM track is depicted in Fig 3 (a) which shows $\mathrm{Ti}$ and $\mathrm{C}$ only. This indicates that the dendrites are mainly TiC. This is due to strong tendency of $\mathrm{Ti}$ and $\mathrm{C}$ to react compared to $\mathrm{Fe}$ and $\mathrm{Si}$ in the melt pool. The

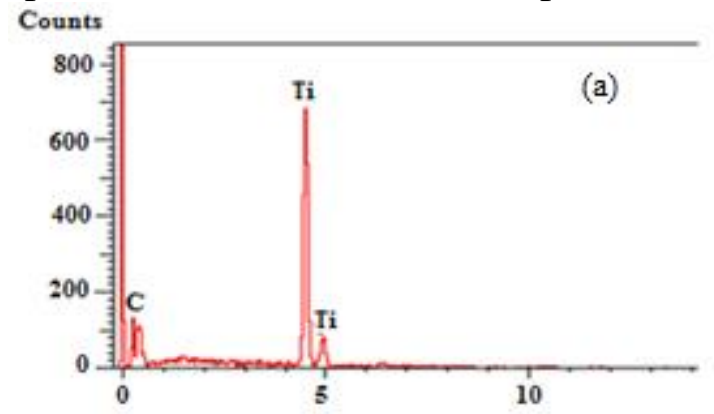

EDX in Fig 3 (b) showed dissolution of preplaced powder mixture in Ti melt matrix. As it can be seen, $\mathrm{Fe} \mathrm{C}$ and $\mathrm{Si}$ were conspicuously present in titanium melt matrix. X-ray diffraction pattern taken from the surface of the sample processed with PPM2 shows TiC (dendrites), $\mathrm{SiC}, \mathrm{Fe}_{3} \mathrm{C}$ and $\mathrm{Ti}_{3} \mathrm{SiC}_{2}$ as the main phases of modified layer.
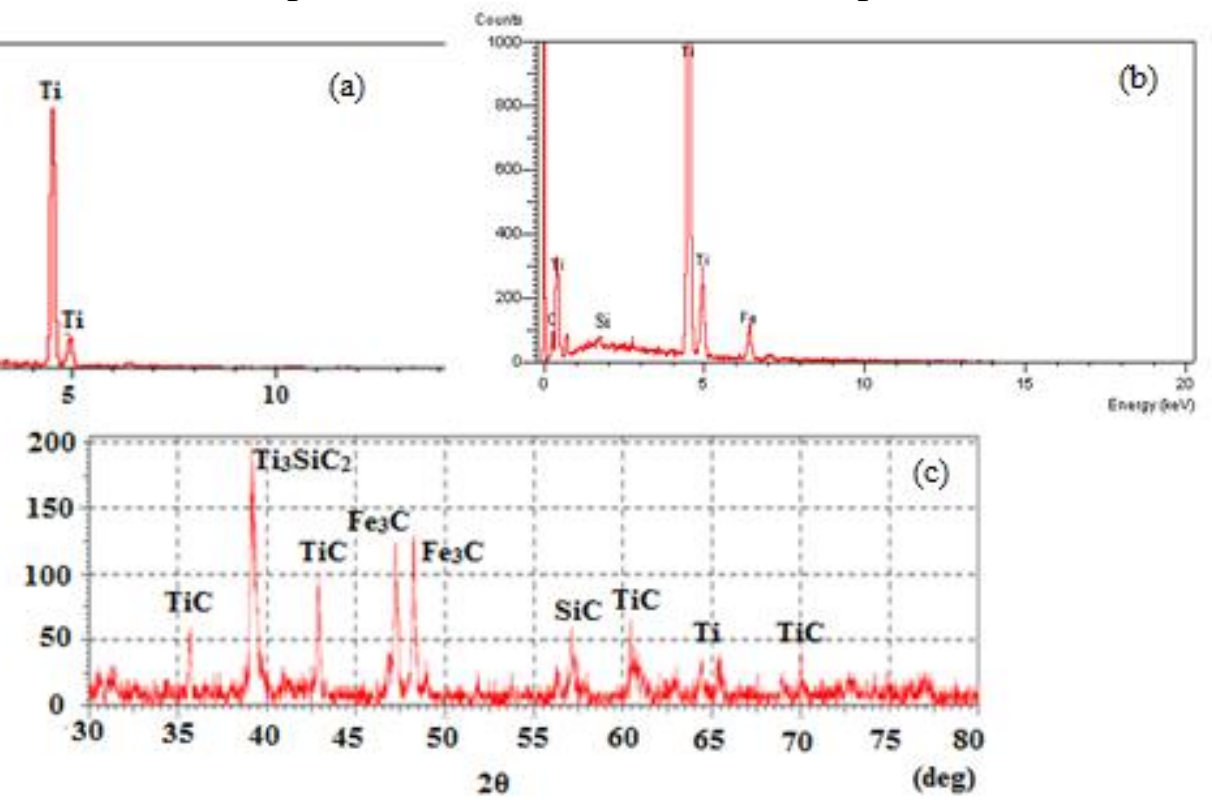

Figure 3 (a) EDX analysis within the dendrite phase, (b) Elemental analysis within Ti melt matrix and (c) X-ray diffraction pattern of PPM2 track at energy input $1350 \mathrm{~J} / \mathrm{mm}$.

\section{B. Microhardness and wear properties of surface modified CP-Ti}

Fig. 4 shows the microhardness value along with the tribological behaviour of PPM tracks. The Vicker hardness values of the various melt cross-sections (PPM) are measured from the surface towards the vertical melt depth. The hardness values plotted against the melt depth are shown in Fig. 4 (a). The surface processed with PPM2 track showed a maximum hardness of $\sim 800$ $\mathrm{HV}_{0.5 \mathrm{kgf}}$ which is 3.5 to 4 times the base hardness (200 $\left.\mathrm{HV}_{0.5} \quad \mathrm{kgf}\right)$. The high microhardness value obtained is due to the formation of hard phases such as $\mathrm{TiC}, \mathrm{Fe}_{3} \mathrm{C}$, $\mathrm{SiC}$ and $\mathrm{Ti}_{3} \mathrm{SiC}_{2}$ in the modified layers shown in Fig 3 (b), detected by X-ray diffraction, among which titanium carbides play a higher effective role. With the powder preplaced mixture (PPM3 track), the maximum 
hardness developed was $470 \mathrm{HV} 0.5 \mathrm{kgf}$ and slightly drops later to $300 \mathrm{HV} 0.5 \mathrm{kgf}$ at 300 $\mu \mathrm{m}$ depth. Compared to the hardness profile produced for PPM1 track, the maximum hardness developed for PPM3 track was lower. The addition of PPM3 created some pores in the Ti melt matrix. The fluidity of the melt reduces with increasing powder preplaced mixture. This low fluidity viscous melt caused difficulty for excess gas to escape from the liquid melt during
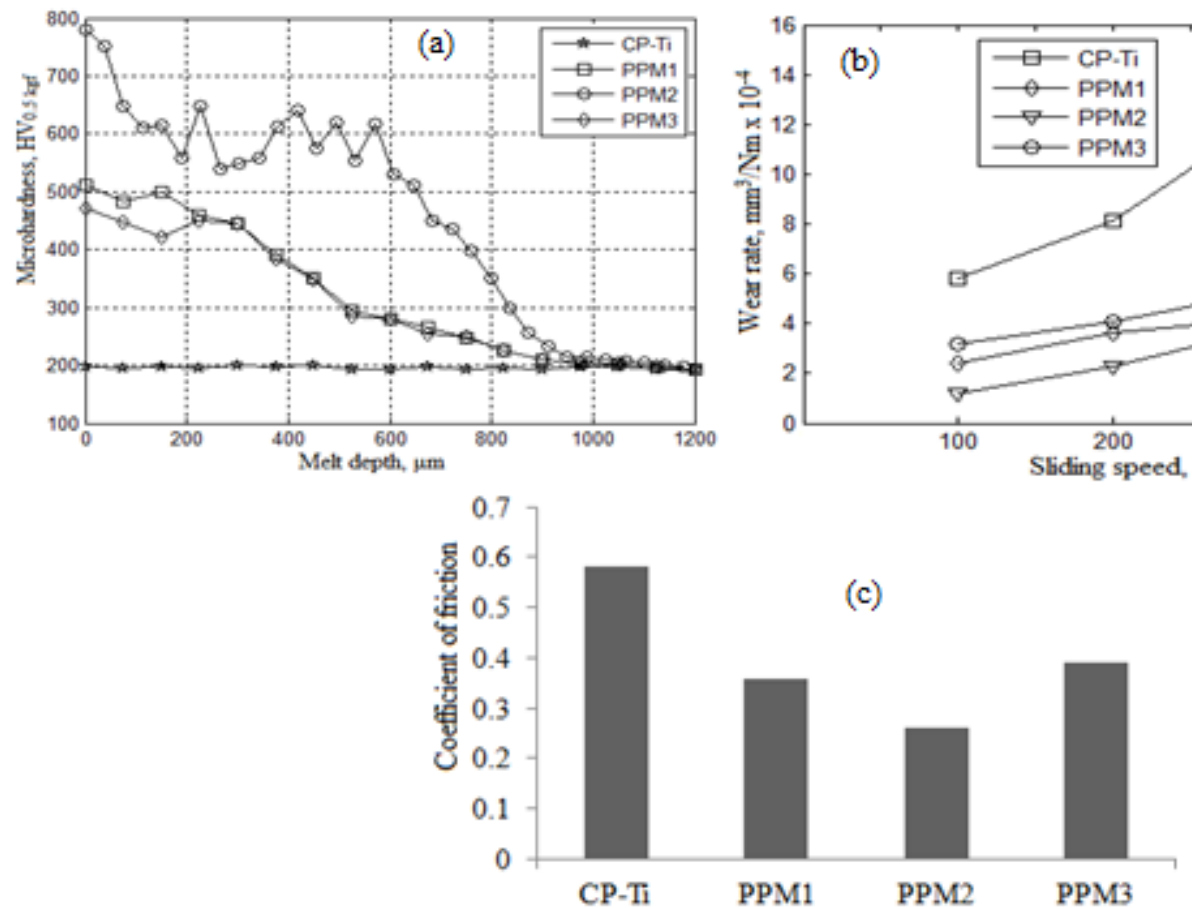

Figure 4 (a) Microhardness of modified layer, (b) Effect of wear rate of modified layer on sliding speed and (c) Frictional behaviour of modified layer at 200 RPM.

Fig. 4 (b) shows the variation in wear rates under different sliding speed for CP-Ti modifying surface. Other parameters such as load, relative humidity are kept constant. It can be seen that the surface modified CP-Ti had a lower wear rate compared to untreated CP-Ti. An increase in sliding speed was noted to lead to an increase in wear rates and loss of the material. The increase in wear rate is due to increase in sliding speed throughout the test. The wear rate is directly related to the melt depth and hardness value of the modified layer. The sample processed with PPM2 showed the lowest wear rate. This is attributed to formation of highest melt depth and hard carbides in the melt pool layer which lead to higher hardness obtained for this specimen. For the specimen processed solidification which has been reported as the cause of pore formation in the melt matrix area. Wang et al. [10] reported that reduction of hardness is mainly due to defects and incomplete fusion of the added particulates in the melt pool layer. The powder preplacement mixture and TIG melting method can produce a thin layer of $\sim 1.2 \mathrm{~mm}$ thickness when processed with PPM2 with a developed maximum hardness of about 800 $\mathrm{HV} 0.5 \mathrm{kgf}$.

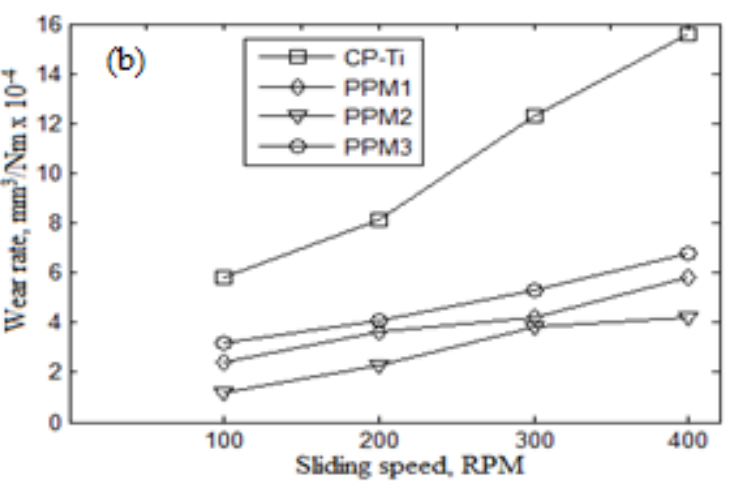

(c)

with PPM1 a significant reduction in wear rate was also noticed. The lower wear rate recorded for this sample might be due to population of $\mathrm{TiC}$ in the microstructure with the corresponding lower melt depth. Comparing PPM3 with PPM1 and PPM2, TIG surface melting of PPM3 showed highest volume wear rate. This is directly attributed to low hardness and defect that characterized this specimen. Thus, the amount, size and bond between the substrate and modified layer are significant parameters in the resistance of material against wear.

Fig. 4 (c) shows the frictional behaviour of $\mathrm{CP}-\mathrm{Ti}$ and modified layers at a constant sliding speed of 200 RPM. It can be seen that the friction coefficient of commercial purity titanium was higher than the modified 
layers. During sliding, the temperature between the contact surfaces gradually changes as the sliding speed increases. This phenomenon leads to the formation of an oxide layer on the sample contact surface thereby resulting lower coefficient of friction. Yoon et al. [17] have reported that during sliding the tribochemical reaction causes the formation of oxides which can also contribute to the reduction of the friction coefficient that was noticed. The friction coefficient for the substrate is 0.58. The friction coefficient of the surface modified with PPM1, PPM2 and PPM3 are 0.32, 0.26

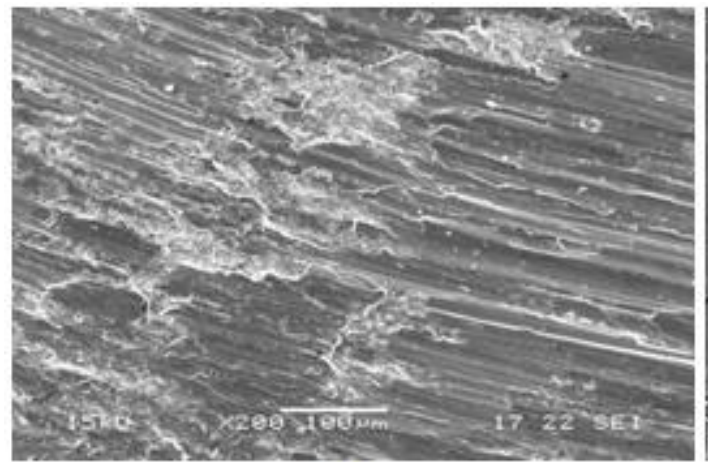

(a)

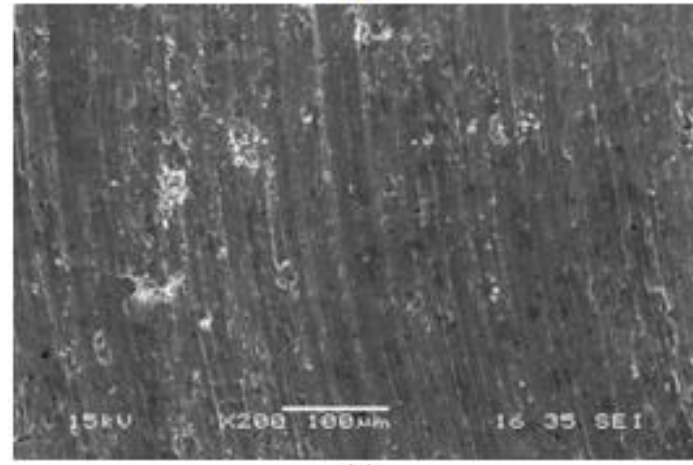

(c) and 0.39 respectively. The friction experiment indicates that increasing the amount of powder composition particles in the coatings can effectively reduce the surface friction coefficient and consequently improves the surface friction resistance for coatings. The significant reduction in friction coefficient recorded can be attributed to higher volume fraction of carbides and hardness in the coating. The effect of higher hardness is to reduce the load transferred to the subsurface, which cause the applied load to be borne mainly by the modified layer.

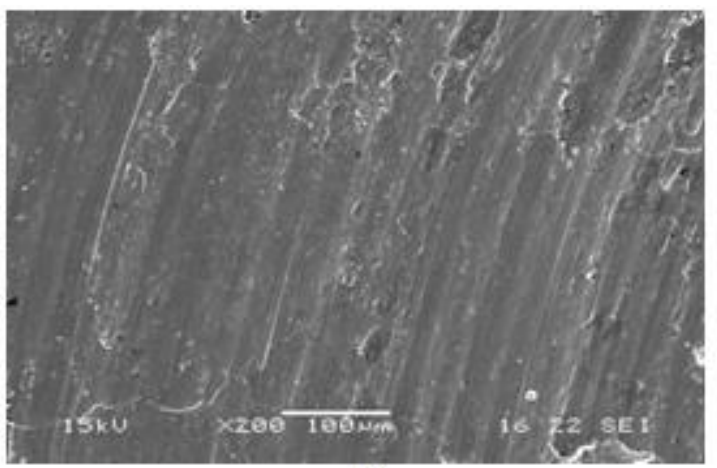

(b)

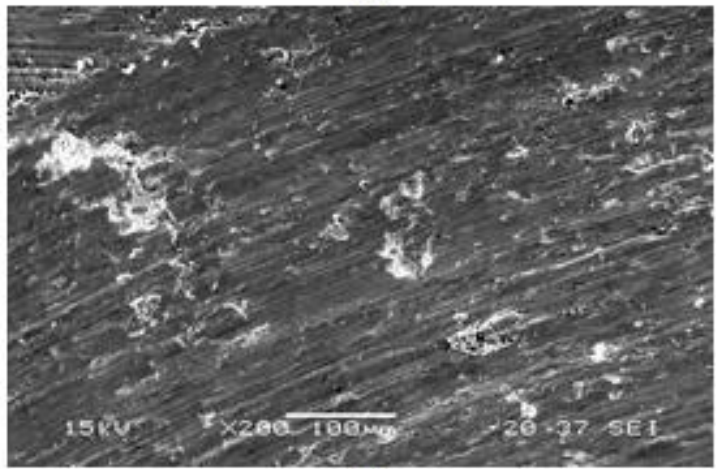

(d)

Figure 5 SEM micrographs showing worn surface: (a) CP-Ti, (b) PPM1, (c) PPM2 and (d) PPM3.

Fig. 5 shows the wear scar of the CP-Ti substrate and the surface modified layer with different powder compositions sliding against alumina $\left(\mathrm{Al}_{2} \mathrm{O}_{3}\right)$ ball under $10 \mathrm{~N}$ normal load. According to Fig. 5 (a) the morphology of the worn surface of the CP-Ti substrate is different to that of the modified layer. For CP-Ti substrate, an extensive typical adhesive wear dominated by plastic deformation is observed while modified layer shows relatively less severe deformation. Due to low hardness and metallic bond nature of the untreated CP-Ti substrate, its surface can be easily plastically deformed, ploughed and transferred resulting in the detachment of large chips and adhesive wear debris. However, for the sample reinforced with PPM1, PPM2 and PPM3, a mild wear surface was observed which indicates that severe plastic deformation and adhesion was prevented. The PPM particles in the Ti melt matrix formed intermetallic compounds which improve the bonding strength between the PPM particles and Ti matrix interface. As a result, the hard carbides formed on the $\mathrm{CP}$ Ti surface do not easily pull out from the matrix during wear sliding. Therefore, the composite coating is found to possess a much 
high wear resistance to plastic deformation which increases the resistance to plastic deformation. The modification of titanium offers several advantages in comparison with the conventional method of using cast iron liner. The coating thickness $(1520 \mu \mathrm{m})$ and hardness (800 HV) of TIG coating of titanium is significantly higher in comparison with thermal sprayed cast iron liner $(500 \mu \mathrm{m}$ and $400 \mathrm{HV}$ ) [18]. In addition a high dendritic structure with good metallurgical bonding of TIG coating gives excellent condition as compared to ferrite phase structure obtained for thermal sprayed coating of traditional cast iron liner.

\section{Conclusions}

In this study $\mathrm{Fe}-\mathrm{C}-\mathrm{Si}$ coatings were fabricated on commercial purity titanium using TIG torch melting technique. The following conclusion may be drawn from the results obtained.

- Three different powder preplaced mixtures 97Fe2C1Si, 94Fe4C2Si and 91Fe6C3Si were successfully modified on CP-Ti. Surface modification with 94Fe4C2Si developed larger melt geometry.

- The melt pool geometry was hemispherical in shape and dendritic microstructure with hard layers containing $\mathrm{TiC}, \mathrm{Fe}_{3} \mathrm{C}, \mathrm{SiC}$ and $\mathrm{Ti}_{3} \mathrm{SiC}_{2}$ phases were observed on surface modified CP-Ti. Coatings produced by TIG with premixed powders showed a good metallurgical bonding with the substrate.

- Due to the presence of hard phases, the hardness of the modified layer reached a value as high as $800 \mathrm{HV} 0.5 \mathrm{kgf}$ which was almost 3 to 4 times as compared to $\mathrm{CP}-\mathrm{Ti}$ base material.

- TIG surface modification with 97Fe2C1Si, 94Fe4C2Si and 91Fe6C3Si on CP-Ti improve the wear resistance, although the surface modified with 94Fe4C2Si is more effective.

\section{Acknowledgements}

The authors wish to thank the Research Management Centre (RMC) of International
Islamic University Malaysia for their financial support through grant RMGS 12007-0020.

\section{References}

[1] A. Merlo, "The contribution of surface engineering to the product performance in the automotive industry," Surface and Coatings Technology, vol. 174, pp. 21-26, 2003.

[2] A. Vaziri, M.H. Sohi, and A. Safaei, "Liquid phase surface alloying of CPtitanium with aluminum in an atmosphere of argon and nitrogen," Surface and Coatings Technology, vol. 206, pp. 3788-3794, 2012. [3] M. Maleque, K.A. Bello, A.N. M Idriss and S. Mridha, "Processing of TiCCNT hybrid composite coating on low alloy steel using TIG torch technique," Applied Mechanics and Materials, vol. 378, pp. 259264, 2013.

[4] M. A. Maleque A. Umma and N Omar, "Wear mechanisms map of CNT-Al nano-composite, Procedia Engineering," vol 12, pp. 247-253, 2013.

[5] E. A. Association, "The aluminium automotive manual," EAA, available at, 2011.

[6] S. A. Adeleke and M. A. Maleque, "Tungsten inert gas surface alloying of commercial purity titanium (CP-Ti) with FeC-Si ternary mixtures," in Advanced Materials Research, pp. 207-210, 2014.

[7] I. Manna, J. Dutta Majumdar, B. Ramesh Chandra, S. Nayak, and N. B. Dahotre, "Laser surface cladding of $\mathrm{Fe}-\mathrm{B}-$ $\mathrm{C}, \mathrm{Fe}-\mathrm{B}-\mathrm{Si}$ and $\mathrm{Fe}-\mathrm{BC}-\mathrm{Si}-\mathrm{Al}-\mathrm{C}$ on plain carbon steel," Surface and Coatings Technology, vol. 201, pp. 434-440, 2006.

[8] H. Sabet, Sh. Khierandish, Sh. Mirdamadi, and M. Goodarzi, "The Microstructure and abrasive wear resistance of $\mathrm{Fe}-\mathrm{Cr}-\mathrm{C}$ hardfacing alloys with the composition of hypoeutectic, eutectic, and hypereutectic at frac $\{\mathrm{Cr}\}\{\mathrm{C}\}=6$," Tribology Letters, vol. 44, pp. 237-245, 2011.

[9] M. A. Maleque and H.H. Masjuki, "Wear surface characteristics study of tribomaterials under palm oil methyl ester added 
lubricant", Industrial Lubrication and Tribology, 54 (4), pp. 177 - 182, 2002.

[10] X. H.Wang, S.L. Song, Z.D. Zou, and S.Y. Qu, "Fabricating TiC particles reinforced Fe-based composite coatings produced by GTAW multi-layers melting process," Materials Science and Engineering: A, vol. 441, pp. 60-67, 2006.

[11] J. O. Agunsoye, S. A. Talabi, I. O. Olumiyiwa, and T. Afemefuna, "Effect of silicon additions on the wear properties of grey cast iron," Journal of Minerals and Materials Characterization and Engineering, vol. 1, pp. 61-67, 2013.

[12] M. Sheikholeslami and S. Boutorabi, "A research on the calculation of graphitization ability of gray cast irons," Iranian Journal of Materials Science \& Engineering, vol. 9, 2012.

[13] S. Kou, "Heat flow in welding," Welding Metallurgy, 2nd ed., pp. 37-64, 2003.

[14] S. Dyuti, S. Mridha, and S. K. Shaha, "Surface modification of mild steel using tungsten inert gas torch surface cladding," American Journal of Applied Sciences, vol. 7, p. 815, 2010.

[15] Z. Jiyang and L. Jincheng, "Colour metallography of cast iron," SCI, vol. 7, 2010.

[16] J. F. Lancaster, Metallurgy of welding: Elsevier, 1999.

[17] S.-Y. Yoon, K.O. Lee, S.S. Khang, and K.H. Kim "Comparison for mechanical properties between TiN and TiAlN coating layers by AIP technique," "Journal of Materials Processing Technology, vol. 130, pp. 260-265, 2002.

[18] G. Barbezat, "Advanced thermal spray technology and coating for lightweight engine blocks for the automotive industry," Surface and Coatings Technology, vol. 200, pp. 1990-1993, 2005. 